\title{
Duration of antibiotic therapy in hospitalised patients with community-acquired
} pneumonia

\author{
S. Aliberti*, F. Blasi*, A.M. Zanaboni”, P. Peyrani", P. Tarsia*, \\ S. Gaito ${ }^{\#}$ and J.A. Ramirez
}

ABSTRACT: Recent guidelines suggest that duration of antibiotic therapy for hospitalized patients with community-acquired pneumonia (CAP) can be reduced by individualising treatment based on patient's clinical response. However, the degree of application of this principle in clinical practice is unknown.

Duration of therapy was analysed in patients identified from the Community-Acquired Pneumonia Organization database and evaluated with respect to severity of the disease on admission and time to clinical stability (TCS).

Among the 2,003 patients enrolled, mean duration of total antibiotic therapy was 11 days. Neither the pneumonia severity index $\left(r^{2}=0.005\right)$ nor the CRB-65 $\left(r^{2}=0.004\right)$ scores were related to total duration of therapy. Duration of intravenous antibiotic therapy was related to TCS $\left(r^{2}=0.198\right)$. Conversely, TCS was not related to duration of either oral $\left(r^{2}=0.014\right)$ or total $\left(r^{2}=0.02\right)$ antibiotic therapy. Neither TCS nor other characteristics were found to be significantly associated with duration of total therapy by logistic regression analysis $\left(r^{2}<0.09\right)$.

The individualised approach suggested by recent guidelines has not been adopted in current clinical practice. Duration of therapy is not influenced by either the severity of disease at the time of hospitalisation or the clinical response to therapy.

KEYWORDS: Antibiotic treatment of pneumonia, community-acquired pneumonia, treatment

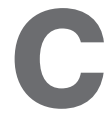
ommunity-acquired pneumonia (CAP) is the leading cause of death from infectious diseases in most developed countries [1,2]. Due to the burden of CAP on morbidity and mortality, healthcare providers must adopt practices focused on improving outcomes. A key measure in doing so is to optimise antibiotic usage.

During recent decades, increasing evidence strengthened the recommendations of guidelines concerning antibiotic selection, early initiation of therapy and the switch from intravenous to oral therapy [3, 4]. Surprisingly, few well-designed studies exist which evaluate the appropriate duration of antibiotic therapy. International guidelines that propose recommendations for duration of therapy in CAP patients are based mostly on expert opinions [5-7]. The different strategies used to develop current recommendations on duration of therapy can be defined as follows: 1) a strategy based on the clinical diagnosis of CAP, which recommends an average 10-14 day duration of therapy for all those hospitalised with a diagnosis of CAP; 2) a strategy based on the aetiology of
CAP, which recommends a specific duration of therapy according to the pathogen isolated; and 3) a strategy based on the antibiotic selected to treat CAP, which recommends a specific duration of therapy according to the particular antibiotic used. Recently, two recommendations regarding duration of therapy have been formulated based on patient characteristics [8]. One, based on the severity of the disease on admission, recommends a longer duration of antibiotic therapy in cases of severe CAP. The other, based on the clinical response to therapy, recommends a shorter duration of antibiotic therapy for patients with an early clinical response and a longer duration of therapy for those with a delayed clinical response. These patient-based strategies can be considered the most comprehensive, because duration of therapy is individualised based on a particular patient's characteristics.

Minimal information appears in the literature regarding actual clinical practice in relation to duration of therapy. The standard practice regarding the number of days antibiotics are used to treat hospitalised patients with CAP is unknown.

\section{AFFILIATIONS}

${ }^{*}$ Dipartimento toraco-polmonare e cardio-circolatorio, University of Milan, IRCCS Fondazione Cà Granda, Ospedale Maggiore Policlinico, and ${ }^{\#}$ Computer Science Dept, University of Milan, Milan, Italy.

"Division of Infectious Diseases, Dept of Medicine, University of Louisville, Louisville, KY, USA.

\section{CORRESPONDENCE}

J.A. Ramirez

Division of Infectious Diseases

Dept of Medicine

University of Louisville

501 East Broadway

Louisville

KY 40202

USA

E-mail: j.ramirez@louisville.edu

Received:

Aug 182009

Accepted after revision:

Nov 022009

First published online:

Nov 192009 
Even though strategies based on severity of disease and clinical response are recommended, there are no data evaluating if these characteristics are used by physicians to determine the duration of antibiotic therapy.

Due to the paucity of information regarding duration of therapy, we designed a study with the following objectives: 1) to define current practice of duration of therapy for hospitalised patients with CAP; and 2) to evaluate if physicians' decisions in determining duration of therapy is influenced by either the severity of disease at the time of hospitalisation or the clinical response to therapy.

\section{MATERIALS AND METHODS}

\section{Study design and subjects}

A secondary analysis of the Community-Acquired Pneumonia Organization (CAPO) database was performed. The database contains data retrospectively collected from 43 hospitals in 12 countries, between June 2001 and June 2005. In each participating centre, primary investigators selected adult nonconsecutively hospitalised patients diagnosed with CAP. All data were collected on a case report form and transferred electronically to the CAPO coordinating centre at the University of Louisville (Louisville, KY, USA). Local institutional review board approval was obtained for each study site.

\section{Inclusion and exclusion criteria}

Patients $\geqslant 18$ yrs of age and satisfying the criteria for CAP were included in this study. Patients with a diagnosis of healthcare-associated pneumonia (HCAP) were excluded from the analysis. In order to investigate primarily the duration of antibiotic therapy prescribed only for the episode of CAP, patients who received antibiotic therapy for either $<3$ days or $>28$ days were considered having another diagnosis rather than CAP and were excluded from the statistical analysis. Patients who died while receiving antibiotic therapy, as well as those for whom the duration of antibiotic therapy was not detectable from the database, were also excluded from the statistical analysis.

\section{Study definition}

CAP was defined as the presence of a new pulmonary infiltrate on chest radiograph at the time of hospitalisation associated with at least one of the following: 1) new or increased cough; 2) an abnormal temperature $\left(<35.6^{\circ} \mathrm{C}\right.$ or $\left.>37.8^{\circ} \mathrm{C}\right)$; and 3$)$ an abnormal serum leukocyte count (leukocytosis, left shift or leukopaenia defined by local laboratory values).

HCAP patients were defined as those with the following risk factors: 1) long-term haemodialysis; and 2) resident in a nursing home or a long-term care facility.

Duration of antibiotic therapy was considered for antibiotics ordered for the episode of CAP both during hospitalisation and after hospital discharge. Duration of antibiotic therapy was analysed as total duration of therapy and duration of intravenous and oral therapy. Total duration of therapy was calculated by subtracting the day the last antibiotic (either intravenous or oral) was discontinued from the day when the first antibiotic (either intravenous or oral) was started. Duration of intravenous therapy was calculated by subtracting the day the last intravenous antibiotic was discontinued from the day when the first intravenous antibiotic was administered on admission. Duration of oral therapy was calculated by subtracting the day the last oral antibiotic was discontinued from the day when the first oral antibiotic was administered.

Time to clinical stability (TCS) was calculated as the number of days from the date of admission to the date the patient met clinical stability criteria. Clinical stability was defined as follows: improved clinical signs (improved cough and shortness of breath), lack of fever for $\geqslant 8 \mathrm{~h}$, improving leukocytosis (decreased $\geqslant 10 \%$ from the previous day), and tolerating oral intake [9]. Criteria for clinical stability were evaluated daily during the first 7 days of hospitalisation. Length of stay in the hospital (LOS) was calculated as the number of days from the date of admission to the date of discharge. LOS was censored at 14 days in an effort to capture only CAP-related LOS, and to prevent the bias of patients who remained hospitalised for social issues.

\section{Statistical analysis}

All statistical analyses were performed with SPSS (version 17.0; SPSS Inc., Chicago, IL, USA) for Mac. A descriptive statistical analysis at baseline was performed and results are reported as mean \pm SD for scale variables and as counts (\%) for nominal variables. Total duration of antibiotic therapy was evaluated with respect to severity of the disease on admission and other covariates, at $95 \%$ confidence level, by mean \pm SD. The association between total duration of therapy and severity indices was investigated using a least squares approach adjusted for regions (USA/Canada, Latin America and Europe) and quality of care indicators (oxygen assessment on admission, assessment of blood cultures, empirical antibiotic therapy in compliance to local guidelines and time to first antibiotic dose); data are presented as least square means $95 \%$ confidence intervals.

A logistic regression was performed in order to evaluate the possible discrimination between a total duration of therapy $<10$ days versus $\geqslant 10$ days in dependence of the following variables: demographics (age), comorbidities (immunosuppression), clinical (altered mental status, alteration of gas exchange, pneumonia severity index (PSI) risk class 4 and 5 , CRB-65 (confusion, respiratory rate $\geqslant 30$ breaths $\cdot \mathrm{min}^{-1}$, low blood pressure (systolic value $<90 \mathrm{mmHg}$ or diastolic value $\leqslant 60 \mathrm{mmHg}$ ) and age $\geqslant 65 \mathrm{yrs}$ ) risk class 3 and 4 , hypotension, mechanical ventilation and admission to intensive care unit (ICU)), laboratory and radiological (multilobar infiltrate) findings on admission, microbiology (pathogen isolated and mixed infection) and empirical antibiotic therapy data (compliance to local guidelines), and factors during hospitalisation (TCS). A p-value $<0.05$ was considered statistically significant.

\section{RESULTS \\ Study population}

A total of 2,003 patients were enrolled during the study period. Baseline demographics, comorbidities, disease severity, clinical, laboratory and radiological findings on admission, microbiology, antibiotic therapy data and outcomes of the study population are summarised in table 1.

\section{Duration of therapy: current clinical practice}

The mean $\pm S D$ duration of total antibiotic therapy among the study population was of $11 \pm 4.7$ days. Distribution of the 


\section{TABLE 1 Baseline demographics, comorbidities, severity of the disease, clinical, laboratory and radiological findings on admission, microbiology and antibiotic therapy data, and outcomes of the study population}

\section{Characteristic}

Study population

\section{Subjects $n$ \\ Demographics \\ Males \\ Age yrs \\ Age $>65$ yrs \\ Comorbidities}

2003

$64.0 \pm 17.9$

$1028(51)$

Congestive heart failure

$352(18)$

COPD

$595(30)$

340 (17)

$254(13)$

Cerebrovascular accident

$72(4)$

Liver disease

$270(13)$

\section{Severity on admission}

Altered mental status

$191(10)$

Admission to ICU

$236(12)$

PSI risk class

II

III

\section{CRB-65 score}

0

1

2

3

4

\section{Physical findings}

Respiratory rate $\geqslant 30$ breaths $\cdot \mathrm{min}^{-1}$

Alteration of gas exchange"

Hypotension $^{+}$

Heart rate $\geqslant 125$ beats $\cdot \mathrm{min}^{-1}$

$239(12)$

$361(18)$

$496(25)$

$720(36)$

$187(9)$

$732(37)$

$911(45)$

$322(16)$

$36(1.9)$

$2(0.1)$

$679(34)$

$89(4)$

$266(13)$

\section{Laboratory values}

Arterial $\mathrm{pH}<7.35$

Sodium $<130 \mathrm{mmol} \cdot \mathrm{L}^{-1}$

Haematocrit $<30 \%$

BUN $>30 \mathrm{mg} \cdot \mathrm{dL}^{-1}$

\section{Radiology findings on CXR}

Multilobar involvement

Pleural effusion

105 (5)

104 (5)

108 (5)

$293(15)$

$530(26)$

$363(26)$

\section{Microbiology}

Pathogen isolated

$459(23)$

Mixed infection

43 (2)

Streptococcus pneumoniae

Haemophilus influenzae

$208(10)$

$71(3.5)$

$57(2.8)$

$26(1.3)$

Pseudomonas aeruginosa

$25(1.2)$

Moraxella catarrhalis

$20(1)$

Mycoplasma pneumoniae

\section{TABLE 1 Continued}

Characteristic

Study population

$\begin{array}{lc}\text { Antibiotic used } & \\ \text { Ceftriaxone } & 814(41) \\ \text { Azithromycin } & 599(30) \\ \text { Levofloxacin } & 595(30) \\ \text { Clarithromycin } & 363(18) \\ \text { Cefotaxime } & 182(9) \\ \text { Amoxicillin/clavulanate } & 158(8) \\ \text { Ampicillin/sulbactam } & 105(5) \\ \text { Empiric antibiotic therapy } & \\ \text { Compliant to local guidelines } & 1,698(85) \\ \text { Monotherapy } & 810(40) \\ \quad \text { Levofloxacin } & 388(19) \\ \text { Double therapy } & 1,193(60) \\ \quad \text { Beta-lactam plus macrolide } & 750(37) \\ \quad \text { Beta-lactam plus fluoroquinolone } & 100(5) \\ \text { Switched from i.v. to p.o. antibiotic } & 1,370(68) \\ \text { Outcome } & \\ \text { Time to clinical stability days } & 3.3 \pm 1.7 \\ \text { Length of stay in the hospital days } & 9.5 \pm 9.6\end{array}$

Data are presented as $\mathrm{n}(\%)$ or mean $\pm \mathrm{SD}$, unless otherwise stated. COPD: chronic obstructive pulmonary disease; ICU: intensive care unit; PSI: pneumonia severity index; CRB-65: confusion, respiratory rate $\geqslant 30$ breaths $\cdot \mathrm{min}^{-1}$, low blood pressure (systolic value $<90 \mathrm{mmHg}$ or diastolic value $\leqslant 60 \mathrm{mmHg}$ ) and age $\geqslant 65 \mathrm{yrs}$; BUN: blood urea nitrogen; CXR: chest radiograph \#: cancer, HIV, chronic steroid use; ": arterial oxygen tension $<60 \mathrm{mmHg}$, arterial oxygen tension/inspiratory oxygen fraction $<300 \mathrm{mmHg}$ or oxygen saturation $<90 \%{ }^{+}{ }^{+}$: systolic blood pressure $<90 \mathrm{mmHg}$ or diastolic blood pressure $<60 \mathrm{mmHg}$

study population according to the total duration of therapy is depicted in figure 1 . The common recommended regimen of 10-14 days was used in 846 patients (42\%), while regimens of $<10$ days and $>14$ days were used in 781 (39\%) and 376 patients $(19 \%)$, respectively. The mean \pm SD durations of

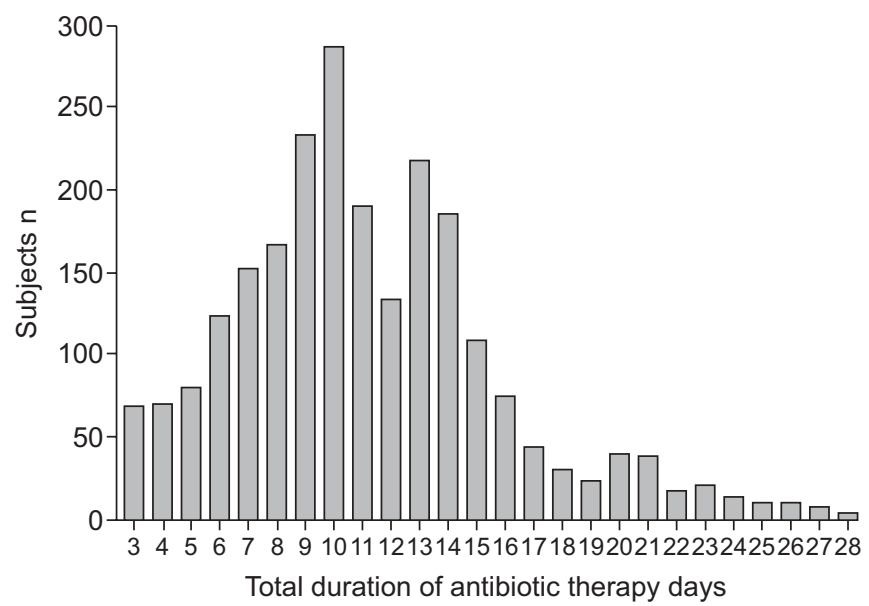

FIGURE 1. Total duration of antibiotic therapy among the study population indicating that the majority of patients are treated for 10-14 days. 
intravenous and oral antibiotic therapy among the study population were of $5.5 \pm 4.8$ and $7.7 \pm 3.8$ days, respectively. Distributions of the study population according to the duration of intravenous and oral antibiotic therapy are depicted in figures 2 and 3 .

No clinical significant differences were observed in the total duration of therapy among either patients $\leqslant 65 \mathrm{yrs}(10 \pm$ 4.9 days) versus those $>65$ yrs (11.2 \pm 4.4 days), or patients with multilobar involvement $(11.5 \pm 5.1$ days $)$ versus those without multilobar involvement $(10.9 \pm 4.6$ days $)$. A total duration of therapy ranging from 10 to 14 days was chosen for patients from which pathogens such as Streptococcus pneumoniae, Haemophilus influenzae, Staphylococcus aureus, Pseudomonas aeruginosa, Mycoplasma pneumoniae and Moraxella catarrhalis were isolated, while a longer duration of therapy was observed when pathogens such as Legionella spp. and Klebsiella pneumoniae (table 2). A slightly higher duration of therapy was found for those patients in which a pathogen was isolated $(12.2 \pm 5.2$ days), in comparison to the others $(10.8 \pm$ 4.5 days; $\mathrm{p}<0.001)$. Total duration of therapy also ranged from 10 to 14 days in patients treated with antibiotic regimens considered to be compliant $(10.9 \pm 4.6$ days $)$ or noncompliant $(12.3 \pm 5.4$ days $)$ according to local guidelines.

\section{Severity of the disease on admission and duration of therapy}

Total duration of therapy was analysed in the study population according to disease severity, taking into account severity scores, clinical and laboratory characteristics on admission (table 3). Severity on admission evaluated by the PSI and the CRB-65 scores has been further investigated in relation to total duration of therapy using regression analysis. No linear relationship was found between either the PSI $\left(\mathrm{r}^{2}=0.005\right)$ or the CRB-65 $\left(r^{2}=0.004\right)$ and the total duration of therapy (fig. 4).

\section{Clinical response and duration of therapy}

Duration of total, intravenous and oral antibiotic therapy is depicted in figure 5, based on the day in which patients reached clinical stability. Using a regression analysis, a linear relationship was found between TCS and duration of intravenous antibiotic therapy $\left(\mathrm{r}^{2}=0.198, \mathrm{p}<0.001\right)$. Conversely, no linear

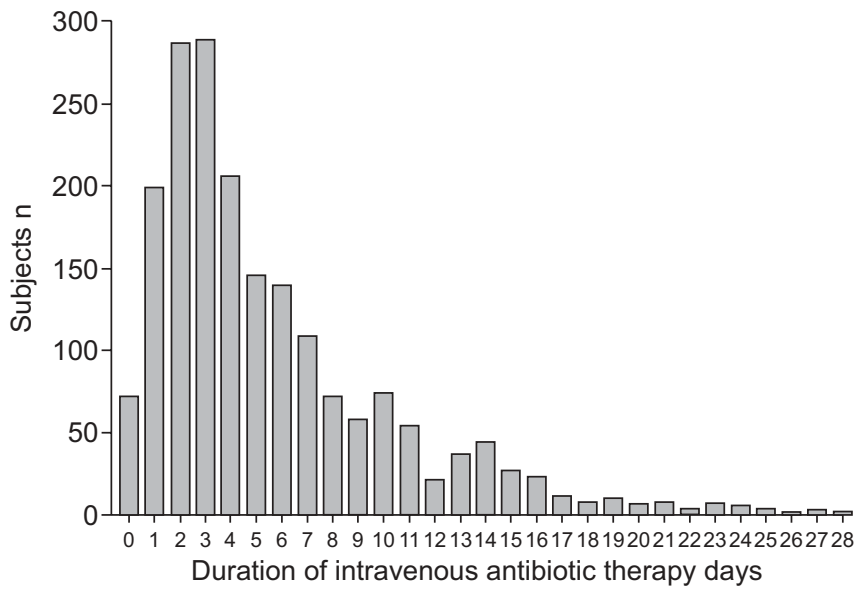

FIGURE 2. Duration of intravenous antibiotic therapy among the study population.

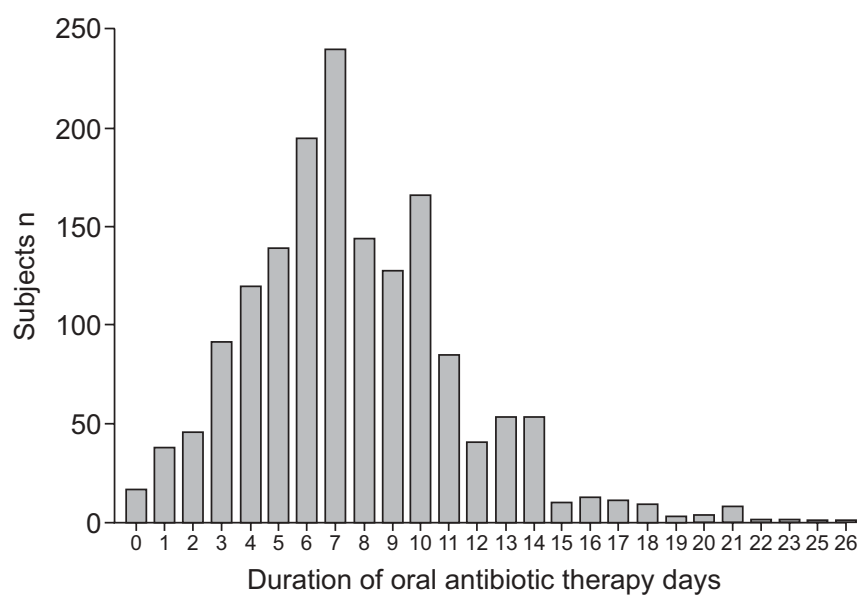

FIGURE 3. Duration of oral antibiotic therapy among the study population.

relationship was identified between TCS and neither the duration of oral antibiotic therapy $\left(\mathrm{r}^{2}=0.014\right)$ nor the total duration of antibiotic therapy $\left(r^{2}=0.02\right)$.

When we applied logistic regression in order to identify variables that could potentially discriminate between a total duration of therapy $<10$ days versus $\geqslant 10$ days, neither TCS nor any other findings were found to be significantly associated with total duration of therapy (R-squared coefficient of determination $<0.09$ ).

\section{DISCUSSION}

Our data indicate that a 10-14 day regimen of antibiotics is the most commonly prescribed duration of therapy in hospitalised patients with CAP. We were unable to find any relationship between total duration of therapy and severity of disease on admission or time to clinical response. Our data suggest that physicians have not embraced the recent recommendations to individualise duration of therapy based on patient characteristics.

Our data suggest that when determining the appropriate duration of therapy, physicians do not consider patient severity on admission. Indeed, we found that duration of therapy was the same regardless of the severity of CAP, as

\begin{tabular}{l|l|}
\hline TABLE 2 & $\begin{array}{c}\text { Total duration of therapy in the study population } \\
\text { according to the pathogen isolated }\end{array}$ \\
\hline Pathogen & $\begin{array}{c}\text { Total duration of antibiotic } \\
\text { therapy days }\end{array}$ \\
\hline Streptococcus pneumoniae & $11.2 \pm 4.7$ \\
Staphylococcus aureus & $12.8 \pm 5.2$ \\
Haemophilus influenzae & $11.5 \pm 4.6$ \\
Pseudomonas aeruginosa & $13.2 \pm 5.7$ \\
Moraxella catarrhalis & $11.4 \pm 2.6$ \\
Mycoplasma pneumoniae & $12.9 \pm 6.0$ \\
Klebsiella pneumoniae & $15.7 \pm 5.3$ \\
Legionella spp. & $17.6 \pm 5.4$ \\
\hline
\end{tabular}

Data are presented as mean \pm SD. 


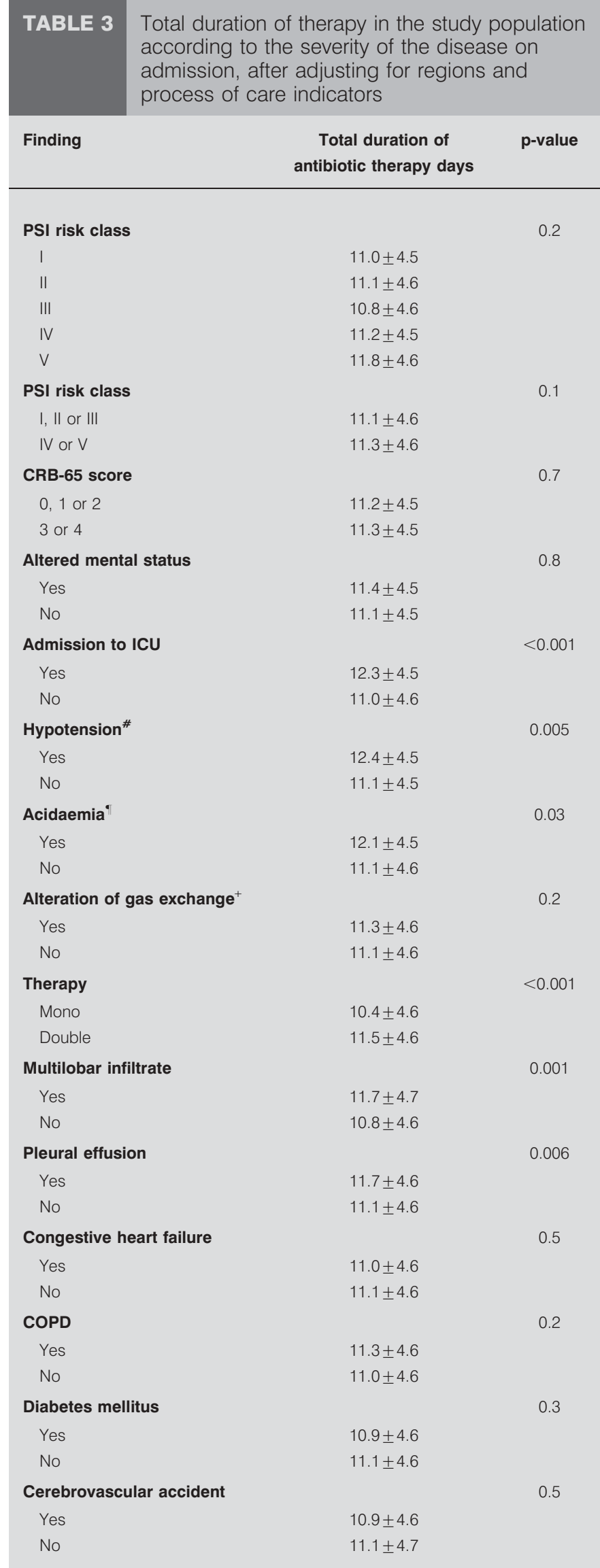

\section{TABLE 3 Continued}

\begin{tabular}{lcc} 
Finding & $\begin{array}{c}\text { Total duration of } \\
\text { antibiotic therapy days }\end{array}$ & p-value \\
\hline $\begin{array}{l}\text { Liver disease } \\
\text { Yes }\end{array}$ & 0.1 \\
No & $11.9 \pm 4.6$ & \\
Immunosuppression & $11.1 \pm 4.7$ & \\
Yes & $11.8 \pm 4.6$ & 0.008 \\
No & $11.0 \pm 4.6$ & \\
\hline
\end{tabular}

Data are presented as mean $\pm \mathrm{SD}$, unless otherwise stated. PSI: pneumonia severity index; CRB-65: confusion, respiratory rate $\geqslant 30$ breaths $\cdot \mathrm{min}^{-1}$, low blood pressure (systolic value $<90 \mathrm{mmHg}$ or diastolic value $\leqslant 60 \mathrm{mmHg}$ ) and age $\geqslant 65$ yrs; ICU: intensive care unit; COPD: chronic obstructive pulmonary disease. " : systolic blood pressure $<90 \mathrm{mmHg}$ or diastolic blood pressure $<60 \mathrm{mmHg}^{\prime}$ ': $\mathrm{pH}<7.35$; ${ }^{+}$: arterial oxygen tension $<60 \mathrm{mmHg}$, arterial oxygen tension/inspiratory oxygen fraction $<300 \mathrm{mmHg}$ or oxygen saturation $<90 \%$; ${ }^{\text {s. }}$ cancer, HIV, chronic steroid use.

evaluated by two severity scores, PSI and CRB-65, as well as the presence of altered mental status, hypotension or abnormal gas exchange on admission. We found that patients admitted to the ICU were treated for one extra day of antibiotic therapy. Even though this 1-day difference was statistically significant, from a clinical perspective no difference could be detected in duration of therapy based on the site of care.

The individualised strategy, based on the patient's clinical stability, can be considered the most comprehensive approach in determining the duration of antibiotic therapy. This is because the patient's clinical response is based on three primary factors: 1) host characteristics, such as immune status and comorbidities; 2) pathogen characteristics, such as its virulence, susceptibility and resistance to antibiotics; and 3) antibiotic characteristics, such as timing, adequacy of therapy and pharmacokinetic factors. The interaction between these three factors characterises each single case of CAP and

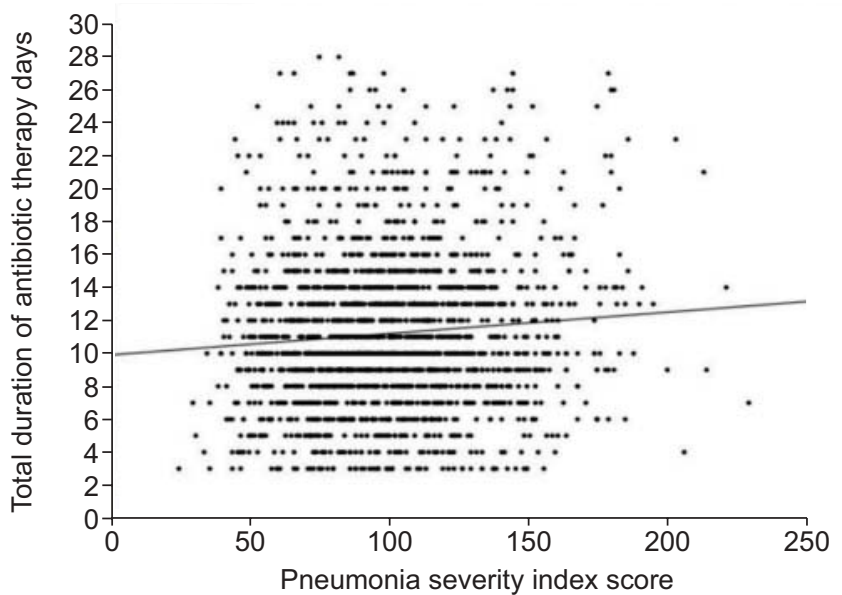

FIGURE 4. Lack of relationship between the pneumonia severity index and total duration of antibiotic therapy in the study population, after adjusting for countries and quality of care indicators. 


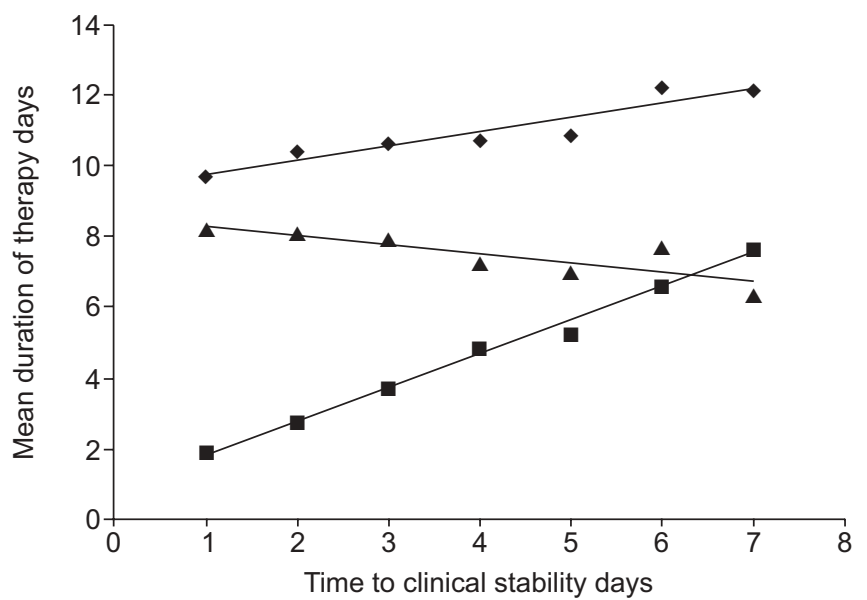

FIGURE 5. Relationship between time to clinical stability and the mean duration of total ( $\bullet p<0.001)$, intravenous $(\boldsymbol{\square} ; p<0.001)$ and oral $(\mathbf{\Delta} ; p=0.002)$ antibiotic therapy in the study population, with $\mathrm{p}$-values for linear trend.

determines the time in which a patient reaches clinical stability. At that point, the bacterial burden in the lung is greatly decreased due to a combination of the immune response and the antibiotic activity; after a short time, the antibiotic could be discontinued.

Using an individualised strategy to determine the duration of antibiotic therapy has been previously tested in patients with hospital-acquired pneumonia [10]. Patients with a low clinical pulmonary infection score received a 3-day course of antibiotics and showed favourable outcomes in comparison to those who received standard care with multiple antibiotics administered for a longer period. In patients affected by CAP, the recommendation of using the TCS in evaluating the duration of therapy remains at the moment an expert opinion. The median time to resolution of fever and the median TCS in CAP patients have been shown to be 3 [11] and 4 days [12]. Therefore, it can be inferred that, on the basis of current recommendations, approximately half of the patients with CAP should be treated for a total duration of 5-6 days [13]. The finding that subsequent deterioration occurred in $<1 \%$ of patients, once clinical stability had been achieved, provides further support of the use of TCS in guiding the duration of antibiotic therapy [14].

When we evaluated the individualised approach in hospitalised patients with CAP, we found that physicians worldwide do not use clinical response when determining the total duration of antibiotic therapy. Particularly, total duration of therapy was generally much longer than the time needed to reach clinical stability. This is perhaps due to the "feeling of protection" that physicians experience when their patients are on antibiotics. On the other hand, the uncertainty regarding the length of antibiotic therapy and the delay in discontinuing antibiotics could have important consequences for both patients and the healthcare system, including the increase in microbial resistances, severe side-effects and costs.

We also evaluated the relationship between TCS and the duration of both intravenous and oral antibiotic therapy. We found that the duration of intravenous therapy is tailored to the patient's clinical response, with more than two-thirds of the population experiencing the switch from intravenous to oral therapy. Conversely, a fixed duration of oral therapy was detected worldwide, ranging from 6 to 8 days, regardless of the patient's clinical response to therapy.

This study identifies trends regarding the relationship between the microorganism isolated and the duration of therapy. When a microbiological diagnosis is obtained, physicians tend to treat CAP patients for a longer period of time, especially if a mixed infection is present. Moreover, when pathogens such as Legionella, K. pneumoniae, P. aeruginosa or S. aureus are isolated, the total duration of antibiotic therapy is longer, in accordance with the suggested guidelines [2].

The "standard approach" of 10-14 days appears to have gained acceptance worldwide as a rule of thumb for duration of antibiotic therapy in hospitalised patients with CAP. Although the rationale for a traditional 10-14 day regimen is observed to be effective in routine clinical practice, this prolonged exposure to antibiotics may encourage the development of, or acquisition of, antibiotic-resistant organisms and may be associated with serious adverse reactions. Furthermore, recent studies indicate that reducing antibiotic treatment to 5 days, compared with the traditional 10-14 days of therapy, may be associated with equivalent efficacy and no adverse outcomes [15].

A limitation of this study is that this is a retrospective observational study; hence, physicians were not asked directly regarding their approach to duration of therapy. However, this study is strengthened by the large patient cohort involving different regions of the world and its lack of exclusion criteria. This suggests that our findings could be generalised to the full population of hospitalised patients with CAP.

Physicians should be encouraged to embrace the recommendations proposed by the most recent Infectious Diseases Society of America and American Thoracic Society guidelines. They specifically recommend that treatment for CAP can be discontinued after a minimum of 5 days in patients who remain afebrile for $42-72 \mathrm{~h}$, provided that no more than one sign of pneumonia-associated clinical instability is present [8]. Since evidence-based findings supporting this approach are limited, future research in this area should include a prospective, randomised, clinical trial enrolling patients that receive antibiotics using the current standard approach versus an individualised strategy based on the patient's clinical response.

In conclusion, this study indicates that the majority of practitioners do not follow the recommended guidelines of using an individualised approach to determine the duration of antibiotic therapy in patients with CAP. Conversely, a standard 10-14 day approach is still used in clinical practice, probably leading to a number of patients remaining on antibiotics for an excessive length of time. Future clinical trials are needed to determine if the individualised approach to shortening the duration of antibiotic therapy could be safely applied in CAP patients, thus decreasing microbial resistance, adverse events and costs.

\section{STATEMENT OF INTEREST}

None declared. 


\section{ACKNOWLEDGEMENTS}

The authors acknowledge the assistance of E. Smigielski, Kornhauser Health Sciences Library, University of Louisville, Louisville, KY, USA. The CAPO investigators and their affiliations are as follows: $R$. Nakamatsu, Veterans Affairs Medical Center, Louisville, KY, USA; F.W. Arnold and M. Allen, University Hospital, Louisville, KY, USA; G. Broch, University of Louisville, Louisville, KY, USA; J. Bordon, Providence Hospital, Washington, DC, USA; P. Gross, Hackensack University Medical Center, Hackensack, NJ, USA; K. Weiss, Maisonneuve-Rosemont Hospital, University of Montreal, Montreal, QC, Canada; D. Legnani, Ospedale L. Sacco, Milan, Italy; M. Bodi, Hospital Universitario Joan XXIII, Tarragona, Spain; A. Torres, Instituto de Neumonologia y Cirugia Toracica, Barcelona, Spain; J. Porras, Hospital Sant Pau i Santa Tecla, Tarragona, Spain; H. Lode, City Hosp. E.v.Behring/Lungenklinik Heckeshorn, Berlin, Germany; J. Roig, Hospital Nostra Senyora de Meritxell, Escaldes, Andorra; G. Benchetrit, IDIM A. Lanari, Buenos Aires, Argentina; J. Corral, Hospital Dr Oscar Alende, Mar del Plata, Argentina; J. Martinez, Instituto Medico Platense, La Plata, Argentina; J. Gonzalez, Hospital Enrique Tornu, Buenos Aires, Argentina; A. Videla, Hospital Universitario Austral, Buenos Aires, Argentina; C. Victorio, Clinica Uruguay, Entre Rios, Argentina; E. Rodriguez, Hospital Espanol de La Plata, La Plata, Argentina; M. Rodriguez, Hospital Rodolfo Rossi, La Plata, Argentina; G. Levy, Hospital Universitario de Caracas, Caracas, Venezuela; F. Arteta, Hospital Luis Gomez Lopez-Ascardio, Barquisimeto, Venezuela; A. Diaz Fuenzalida, Pontifica Universidad de Chile, Santiago, Chile; M. Parada, Clinica las Condes, Santiago, Chile; J. Luna, Hospital Nacional Roosevelt, Guatemala.

\section{REFERENCES}

1 National Center for Health Statistics. Health, United States, 2006; with chartbook on trends in the health of Americans. www.cdc. gov/nchs/data/hus/hus06.pdf Date last accessed: January 17, 2007.

2 Woodhead M, Blasi F, Ewig S, et al. Guidelines for the management of adult lower respiratory tract infections. Eur Respir J 2005; 26: $1138-1180$.

3 Ramirez JA, Vargas S, Ritter GW, et al. Early switch from intravenous to oral antibiotics and early hospital discharge: a prospective observational study of 200 consecutive patients with communityacquired pneumonia. Arch Intern Med 1999; 159: 2449-2454.
4 Oosterheert JJ, Bonten MJ, Schneider MM, et al. Effectiveness of early switch from intravenous to oral antibiotics in severe community acquired pneumonia: multicentre randomised trial. BMJ 2006; 333: 1193-1195.

5 Mandell LA, Bartlett JG, Dowell SF, et al. Update of practice guidelines for the management of community-acquired pneumonia in immunocompetent adults. Clin Infect Dis 2003; 37: 14051433.

6 Macfarlane J, Boswell T, Douglas G, et al. BTS guidelines for management of community acquired pneumonia in adults -2004 update. London, British Thoracic Society, 2004. Available from: www.brit-thoracic.org.uk/c2/uploads/MACAPrevisedApr04.pdf

7 Mandell LA, File TM Jr. Short-course treatment of communityacquired pneumonia. Clin Infect Dis 2003; 37: 761-763.

8 Mandell LA, Wunderink RG, Anzueto A, et al. Infectious Diseases Society of America/American Thoracic Society consensus guidelines on the management of community-acquired pneumonia in adults. Clin Infect Dis 2007; 44: S27-S72.

9 Niederman MS, Mandell LA, Anzueto A, et al. Guidelines for the management of adults with community-acquired pneumonia. Diagnosis, assessment of severity, antimicrobial therapy, and prevention. Am J Respir Crit Care Med 2001; 163: 1730-1754.

10 Singh N, Rogers P, Atwood CW, et al. Short-course empiric antibiotic therapy for patients with pulmonary infiltrates in the intensive care unit. Am J Respir Crit Care Med 2000; 162: 505-511.

11 Metlay JP, Atlas SJ, Borowsky LH, et al. Time course of symptom resolution in patients with community-acquired. Respir Med 1998; 92: 1137-1142.

12 Menéndez R, Torres A, Rodríguez de Castro F, et al. Reaching stability in community-acquired pneumonia: the effects of the severity of disease, treatment, and the characteristics of patients. Clin Infect Dis 2004; 39: 1783-1790.

13 File Jr TM. Clinical efficacy of newer agents in short-duration therapy for community-acquired pneumonia. Clin Infect Dis 2004; 39: S159-S164.

14 Halm EA, Fine MJ, Marrie TJ, et al. Time to clinical stability in patients hospitalized with community-acquired pneumonia: implications for practice guidelines. JAMA 1998; 279: 1452-1457.

15 Li JZ, Winston LG, Moore DH, et al. Efficacy of short-course antibiotic regimens for community-acquired pneumonia: a metaanalysis. Am J Med 2007; 120: 783-790. 